\section{Commentary: Putting the personal back in precision medicine}

\author{
Jacquelyn A. Quin, MD, MPH
}

Even as transcatheter aortic valve replacement gains increasing prominence in the management of patients with aortic valve disease, ${ }^{1,2}$ requisite concerns over the impact of postimplantation thrombus formation remain. ${ }^{3}$ In this regard, Trusty and colleagues ${ }^{4}$ present a particularly novel investigation examining the influence of flow stasis on thrombus formation in the implanted valve's neosinuses - the space between the valve leaflet and the stent itself. Based on measurements taken from posttranscatheter aortic valve replacement computed tomography scans obtained within a year after valve implantation, the investigators created near-exact 3-dimensional-printed replicas of such valves, including size, type, and implantation specifications, for 23 individual patients. The created models were connected to a left heart simulator, dye was serially injected into each individual coronary sinus, and the times needed for dye dissipation were measured. Investigators found that these dye washout times, used as a surrogate for flow stasis, correlated with the degree of thrombus burden visualized on computed tomography imaging for the corresponding neosinuses.

From a practical standpoint, one might be quick to see the study's possible flaws despite its elegant execution by the collaborating biomedical engineers and clinicians. The correlation of flow stasis with thrombus, statistical significance notwithstanding, was not overwhelming. Principles of Virchow's triad, loosely applied, ${ }^{5}$ may lead some to believe the study conclusions were largely anticipated. Last, but not least—it's an in vitro study. Given various assumptions

\footnotetext{
From the Cardiac Division, Department of Surgery, VA Boston Healthcare System, West Roxbury, Mass.

Disclosures: The author reported no conflicts of interest.

The Journal policy requires editors and reviewers to disclose conflicts of interest and to decline handling or reviewing manuscripts for which they may have a conflict of interest. The editors and reviewers of this article have no conflicts of interest.

Received for publication Nov 6, 2020; revisions received Nov 6, 2020; accepted for publication Nov 8, 2020; available ahead of print Nov 20, 2020.

Address for reprints: Jacquelyn A. Quin, MD, MPH, VA Boston Healthcare System, 1400 VFW Parkway, Mail Code 112, West Roxbury, MA 02132 (E-mail: jacquelyn.quin@va.gov).

J Thorac Cardiovasc Surg 2022;164:e125-6

0022-5223/\$0.00

Published by Elsevier Inc. on behalf of The American Association for Thoracic Surgery

https://doi.org/10.1016/j.jtcvs.2020.11.030
}

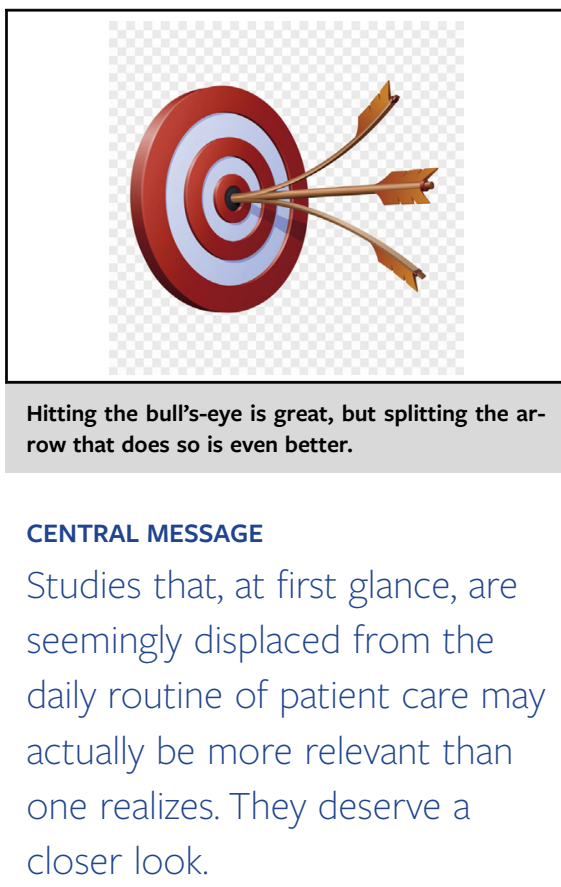

needed to interpret findings, the temptation to view the investigation as far displaced from the here and now of daily clinical practice is undeniable.

There is virtue in being pragmatic. However, from a visionary standpoint, one sees this investigation in a completely different light. Its noteworthy power lies in the recognition that, in this day and age, best practice medicine mandates that optimal antithrombotic strategies be distinctly tailored to the singular patient's unique circumstances. As such, while this patient-specific model is focused on the mechanical aspects of thrombus formation, the investigation itself is a declarative first step toward the concept of individualized antithrombotic management after valve implantation-applicable to all, regardless of valve type or implantation technique.

In 2011, the Institute of Medicine advised changing the term "personalized medicine" to "precision medicine," thus avoiding the misconception that advances in medicine that render it more precise would also render it more personal. ${ }^{6}$ Perhaps the study by Trusty and colleagues will make way for a new paradigm that incorporates the best of these 2 worlds: "personalized, precision medicine." Why just hit the bull's-eye if we can we can split the arrow that does so? Given the advanced imaging and prototype technology already in existence, the practical application of this concept might not be as far away in the distant future as the pragmatist in us imagines. 


\section{References}

1. Elbadawi A, Saad M, Elgendy IY, Barssoum K, Omer MA, Soliman A, et al. Temporal trends and outcomes of transcatheter versus surgical aortic valve replacement for bicuspid aortic valve stenosis. JACC Cardiovasc Interv. 2019;12:1811-22.

2. Goldsweig AM, Tak HJ, Chen LW, Aronow HD, Shah B, Kolte DS, et al. The evolving management of aortic valve disease: 5-year trends in SAVR, TAVR, and medical therapy. Am J Cardiol. 2019;124:763-71.

3. Marwan M, Mekkhala N, Göller M, Röther J, Bittner D, Schuhbaeck A, et al. Leaflet thrombosis following transcatheter aortic valve implantation. $J$ Cardiovasc Comput Tomogr. 2018;12:8-13.
4. Trusty PM, Bhat SS, Sadri V, Salim MT, Funnell E, Kamioka N, et al. The role of flow stasis in transcatheter aortic valve leaflet thrombosis. J Thorac Cardiovasc Surg. 2022;164:e105-17.

5. Lowe GD. Virchow's triad revisited: abnormal flow. Pathophysiol Haemost Thromb. 2004;33:455-7.

6. National Research Council (US) Committee on A Framework for Developing a New Taxonomy of Disease. Toward Precision Medicine: Building a Knowledge Network for Biomedical Research and a New Taxonomy of Disease. Washington, DC: National Academies Press; 2011. Available at: https://www.ncbi.nlm.nih.gov/ books/NBK91503. Accessed November 4, 2020. 